\title{
Protective effects of luteolin against lipopolysaccha- ride-induced acute lung injury involves inhibition of MEK/ERK and PI3K/Akt pathways in neutrophils
}

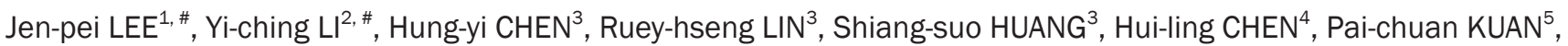
Mao-fang $\mathrm{LIAO}^{6}$, Chun-jung $\mathrm{CHEN}^{7, *}$, Yu-hsiang $\mathrm{KUAN}^{2, *}$

\begin{abstract}
${ }^{1}$ Department of Neurosurgery, Da-Chien General Hospital, Miaoli, Taiwan, China; ${ }^{2}$ Department of Pharmacology, School of Medicine, Chung Shan Medical University and Chung Shan Medical University Hospital, Taichung, Taiwan, China; ${ }^{3}$ Institute of Pharmacy, China Medical University, Taichung, Taiwan, China; ${ }^{4}$ Department of Pharmacy, Da-Chien General Hospital, Miaoli, Taiwan, China; ${ }^{5}$ Public Health Bureau Taoyuan County Government, Taoyuan, Taiwan, China; ${ }^{6}$ Department of Internal Medicine, Fong-Yuan Hospital Department of Health Executive Yuan, Taichung, Taiwan, China; ${ }^{7}$ Department of Education and Research, Taichung Veterans General Hospital, Taichung, Taiwan, China
\end{abstract}

\begin{abstract}
Aim: To investigate whether luteolin, the major polyphenolic components of Lonicera japonica, has beneficial effects against lipopolysaccharide (LPS)-induced acute lung injury (ALI) and to determine whether the protective mechanism involves anti-inflammatory effects on neutrophils.

Methods: ALI was induced with intratracheal instillation of LPS in mice. The level of ALI was determined by measuring the cell count and protein content in bronchoalveolar lavage (BAL) fluid. Neutrophils were stimulated with formyl-Met-Leu-Phe (fMLP) or LPS in vitro. Chemotaxis and superoxide anion generation were measured to evaluate neutrophil activation. The potential involvement of intracellular signaling molecules in regulating neutrophil activation was analyzed by using Western blot.

Results: LPS induced ALI in mice, as evidenced with leukocyte infiltration and protein leakage into the lungs. Luteolin attenuated LPSinduced leukocyte infiltration and protein extravasation. In cell studies, luteolin attenuated the fMLP-induced neutrophil chemotaxis and respiratory burst $\left(\mathrm{IC}_{50} 0.2 \pm 0.1 \mu \mathrm{mol} / \mathrm{L}\right.$ and $2.2 \pm 0.8 \mu \mathrm{mol} / \mathrm{L}$, respectively), but had a negligible effect on superoxide anion generation during phorbol myristate acetate stimulation. Furthermore luteolin effectively blocked MAPK/ERK kinase 1/2 (MEK), extracellular signal-regulated kinase (ERK), and Akt phosphorylation in fMLP- and LPS-stimulated neutrophils.

Conclusion: These results indicate that luteolin has beneficial effects against LPS-induced ALI in mice, and the attenuation of neutrophil chemotaxis and respiratory burst by luteolin involves the blockade of MEK-, ERK-, and Akt-related signaling cascades.
\end{abstract}

Keywords: acute lung injury; chemotaxis; luteolin; mitogen activated protein kinase; neutrophils; respiratory burst; PI3K/Akt

Acta Pharmacologica Sinica (2010) 31: 831-838; doi: 10.1038/aps.2010.62; published online 21 June 2010

\section{Introduction}

ALI is a cause of acute respiratory failure that develops in patients from a variety of clinical disorders, including sepsis, pneumonia, aspiration of gastric and oropharyngeal contents, and major trauma. It is characterized by refractory hypoxemia, acute respiratory distress, and bilateral pulmonary infiltrates, and it is often associated with multiple organ failure

\footnotetext{
\# These two authors contributed equally to the study.

* To whom correspondence should be addressed.

E-mail kuanyh@csmu.edu.tw (Yu-hsiang KUAN); cjchen@vghtc.gov.tw (Chun-jung CHEN)

Received 2010-02-06 Accepted 2010-04-29
}

in the later stage ${ }^{[1]}$. Clinically, ALI is a common complication of infection by Gram negative bacteria and an important cause of morbidity and mortality among humans ${ }^{[2]}$. LPS, an outer membrane component of Gram negative bacteria, can cause serious multiple organ dysfunctions, particularly within the respiratory system ${ }^{[3]}$. Therefore, LPS might be a determinant pathogenic molecule in the initiation and/or propagation of certain cases of ALI.

The histological changes of pulmonary microvascular permeability and neutrophilic inflammatory responses are hallmarks of the early stage of $\mathrm{ALI}^{[1]}$. Accumulating evidence suggests that neutrophils play a critical role in $\mathrm{ALI}^{[4,5]}$. In general, neutrophils are the first line players of the 
host defense system. Through chemotaxis, degranulation, respiratory burst, and phagocytosis, neutrophils migrate from the peripheral blood to the injured sites and ingest invasive pathogens. However, excessive neutrophilic activation releases toxic ROS, cytokines, and proteolytic enzymes, leading to tissue destruction ${ }^{[6-8]}$. The released products from activated neutrophils disrupt alveolar-capillary integrity, amplify inflammatory reactions, damage pulmonary cells, and contribute to lung injury ${ }^{[9]}$. Due to their mediating role, neutrophils are an important target for therapeutic intervention against ALI. Thus, the inhibition of excessive neutrophil activation by blocking chemotaxis and toxic mediator release may present a useful strategy for the treatment of various inflammatory diseases including ALI.

In Chinese medicine, honeysuckle (Lonicera japonica) has been widely used for the treatment of upper respiratory tract infections. The beneficial effects of Lonicera japonica are attributable to its anti-inflammatory properties ${ }^{[10]}$. Among the bioactive components of Lonicera japonica, luteolin (3', 4', 5,7-tetrahydroxyflavone) is an active polyphenolic compound possessing anti-inflammatory activity and is widely distributed in the plant kingdom ${ }^{[11,12]}$. Recent studies have demonstrated remarkable beneficial actions of luteolin through its anti-inflammatory activity. The research of modern scientists has shed new light on honeysuckle in the treatment of SARS and H1N1 influenza ${ }^{[13-15]}$. Luteolin protects mice against LPSinduced toxicity, alleviates bronchoconstriction and airway hyperreactivity in ovalbumin-sensitized mice, and decreases Chlamydia pneumoniae infection-induced inflammatory reactions ${ }^{[16-18]}$. In vitro, luteolin inhibits $\mathrm{NO}$ and pro-inflammatory cytokine expression in primary bone marrow-derived macrophages, gingival fibroblasts, alveolar macrophages, mast cells, and RAW 264.7 cells $^{[19-22]}$. Studies also show that luteolin has a modulatory effect on neutrophils ${ }^{[16,23,24]}$. These observations imply that luteolin may be useful for mitigating inflammation. Given that ALI is characterized by a diffuse inflammatory process, including neutrophil accumulation/ activation, increased vascular permeability, and parenchymal injury, the present study was designed to determine whether luteolin could ameliorate ALI induced by LPS in mice in an attempt to clarify the underlying molecular basis with a focus on neutrophil activation.

\section{Materials and methods Materials}

HBSS and calcein-AM were obtained from Invitrogen. Mouse polyclonal antibodies against Akt, p38 MAPK, ERK, and MEK were obtained from Santa Cruz Biotechnology. Rabbit polyclonal antibodies against phospho-MEK, ERK, p38 MAPK, and Akt were purchased from Cell Signaling Technology. Secondary antibodies were obtained from Jackson ImmunoResearch Laboratories. Liu's stain kit was purchased from Tonyar Biotechnology (Taiwan). The FluoroBlok ${ }^{\mathrm{TM}}$ Insert System was obtained from BD Biosciences. Other chemicals were purchased from Sigma-Aldrich. The final volume of DMSO in the reaction mixture was $<0.5 \%$.

\section{Murine model of ALI}

Male ICR mice (20-25 g) were obtained from BioLASCO (Taiwan). To determine the preventive effect of luteolin on LPSinduced ALI, mice were divided into five groups ( $n=6 /$ group). Various doses of luteolin $(18,35$, and $70 \mu \mathrm{mol} / \mathrm{kg})$ or normal saline were intraperitoneally administered $0.5 \mathrm{~h}$ before a single intratracheal injection of LPS $(100 \mu \mathrm{g} / 50 \mu \mathrm{L})^{[25]}$. To determine the therapeutic effect of luteolin on LPS-induced ALI, mice were divided into three groups ( $n=6 /$ group). Luteolin (70 $\mu \mathrm{mol} / \mathrm{kg}$ ) or normal saline was intraperitoneally administered 5 min after intratracheal LPS administration. Animals that received normal saline $(50 \mu \mathrm{L})$ pretreatment and challenge were referred to as the control group. Six hours after saline or LPS administration, mice were anesthetized with sodium pentobarbital $(60 \mathrm{mg} / \mathrm{kg}$ ). The lungs were lavaged in situ via tracheal cannula with five $1-\mathrm{mL}$ aliquots of sterile saline, and the BAL was centrifuged. Total white blood cells and protein content were determined by counting the cells and using BioRad protein assay reagents in the pellet and supernatant, respectively. All experiments were approved by the Institutional Animal Ethics Committee and conducted in accordance with the principles and guidelines of the US National Institutes of Health Guide for the Care and Use of Laboratory Animals.

\section{Isolation of neutrophils}

The blood of Sprague-Dawley rats was collected from the abdominal aorta. Neutrophils were purified by dextran sedimentation, centrifugation through Ficoll-Paque, and hypotonic lysis of erythrocytes ${ }^{[26]}$. Purified neutrophils, containing $>95 \%$ viable cells, were resuspended in HBSS containing $10 \mathrm{mmol} / \mathrm{L}$ HEPES, pH 7.4, and $4 \mathrm{mmol} / \mathrm{L} \mathrm{NaHCO}_{3}$ and kept in an ice bath before use.

\section{Chemotaxis assay}

The chemotaxis assay was performed using FluoroBlok Insert Systems according to the manufacturer's instructions ${ }^{[25]}$. Briefly, neutrophils $\left(1 \times 10^{7}\right.$ cells $\left./ \mathrm{mL}\right)$ were incubated with 5 $\mu \mathrm{mol} / \mathrm{L}$ calcein-AM for $15 \mathrm{~min}$ at $37^{\circ} \mathrm{C}$. After being washed, the cells were resuspended in HBSS containing $1 \%$ bovine serum albumin. Calcein-labeled cells were placed in FluoroBlok Inserts in the presence or absence of $0.1 \mu \mathrm{mol} / \mathrm{L} \mathrm{fMLP}$. Chemotaxis was measured by detecting the fluorescence of cells that had migrated through the pores $(3 \mu \mathrm{m})$ to the lower chamber. Fluorescence changes, termed RFUs, were monitored at $535 \mathrm{~nm}$ with excitation at $488 \mathrm{~nm}$ using a fluorescence microplate reader.

\section{Measurement of superoxide anion generation}

The generation of superoxide anion in neutrophils was determined by the superoxide dismutase-inhibitable reduction of ferricytochrome $c^{[25]}$. Briefly, the assay mixture contained a neutrophil suspension $\left(2 \times 10^{6}\right.$ cells $)$ and $40 \mu \mathrm{mol} / \mathrm{L}$ of ferricytochrome $c$ in a final volume of $1.5 \mathrm{~mL}$. Absorbance changes in the reduction of ferricytochrome $c$ were monitored at 550 $\mathrm{nm}$ using a microplate reader. 


\section{Western blot analysis of protein phosphorylation}

Neutrophils $\left(2 \times 10^{7}\right.$ cells $\left./ \mathrm{mL}\right)$ were incubated with different concentrations of luteolin for $10 \mathrm{~min}$ before stimulation. The reactions were terminated with a 5 fold volume of cold HBSS. Cellular proteins were extracted with Laemmli sample buffer $^{[25]}$. Proteins (60 $\mu$ g per lane) were resolved by $10 \%$ SDSPAGE and then transferred to polyvinylidene difluoride membranes. The membranes were blocked with $5 \%(w / v)$ nonfat dried milk and probed with anti-phospho-p38 MAPK, antiphospho-Akt, anti-phospho-ERK, or anti-phospho-MEK antibodies. The blots were then stripped and reprobed with antip38 MAPK, anti-ERK, anti-Akt or anti-MEK antibodies to standardize protein loading. The membranes were then incubated with horseradish-peroxidase-conjugated secondary antibody. Detection was performed with the enhanced chemiluminescence reagent. The intensities of the protein bands were determined with a computer image analysis system (Multi Gauge; Fujifilm Corporation).

\section{Statistical analysis}

Statistical analyses were performed using ANOVA followed by the Bonferroni $t$ test for multigroup comparisons; $P<0.05$ was considered significant for all tests. The curve estimation regression analysis with a logarithmic model (Excel) was used to calculate $\mathrm{IC}_{50}$ values.

\section{Results}

The beneficial effect of luteolin on LPS-induced ALI in mice

To demonstrate an effect of luteolin on ALI, a LPS-induced ALI mouse model was used. The central features of the pathogenesis of ALI are enhancement of vascular leakage and leukocyte infiltration in the lung ${ }^{[26-29]}$. Intratracheal administration of LPS induced an increase in pulmonary permeability. An increase in leukocyte infiltration (Figure 1A, $P<0.01$ ) and protein leakage (Figure $1 \mathrm{~B}, P<0.01$ ) in the lung were also detected in LPS-treated mice. The LPS-induced leukocyte infiltration and protein leakage were attenuated by pretreatment with luteolin in a concentration-dependent manner, and statistically significant differences were observed starting at a dose of $35 \mu \mathrm{mol} / \mathrm{kg}$ (Figure 1). Since luteolin shows preventive effects against LPS-induced ALI in mice, we wondered whether luteolin possesses a therapeutic effect. We found that posttreatment with luteolin also attenuated LPSinduced leukocyte infiltration (Figure 2A) and protein leakage (Figure 2B) in the lung. These results suggest that luteolin treatment can protect against LPS-induced ALI in mice, likely through the attenuation of LPS-induced vascular permeability changes and the reduction of leukocyte infiltration in the lung.

\section{Effects of luteolin on neutrophil chemotaxis and the respiratory} burst

The rapid accumulation and activation of neutrophils in the lung is a recognizable event and plays a critical role in the pathogenesis of $\mathrm{ALI}^{[30]}$. To obtain further insight into the protective effects of luteolin against ALI, a mechanistic study was conducted using a cultured neutrophil model. fMLP
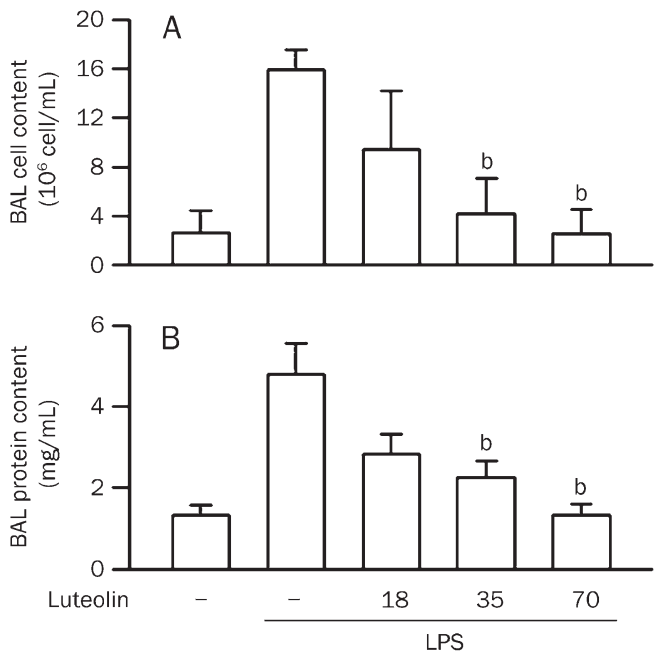

Figure 1. Effect of luteolin on LPS-induced ALI in mice. (A) Normal saline or various doses of luteolin $(18-70 \mu \mathrm{mol} / \mathrm{kg})$ were intraperitoneally administered $0.5 \mathrm{~h}$ prior to intratracheal instillation of LPS $(100 \mu \mathrm{g} / 50 \mu \mathrm{L}$ saline) or normal saline in mice. Six hours later, the mice were sacrificed and used to collect BAL fluid for leukocyte counts. (B) Lung permeability was determined by quantitating the protein content in cell-free BAL. Values are expressed as means \pm SD. $n=5$. ${ }^{b} P<0.05$ vs corresponding LPS-challenged control values (column 2).
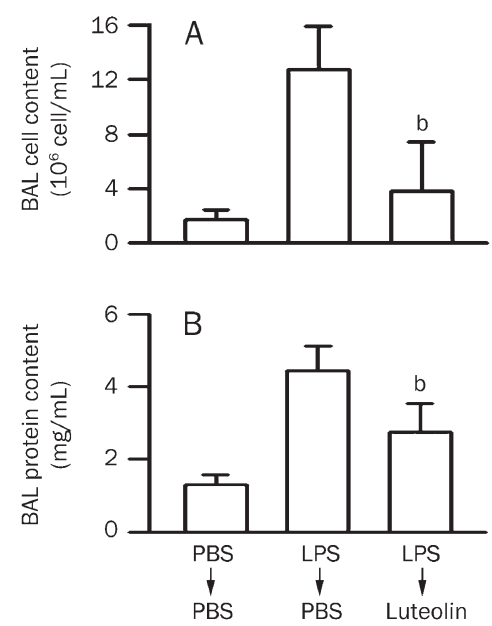

Figure 2. Therapeutic effect of luteolin on LPS-induced ALI in mice. (A) LPS or normal saline were intratracheally injected 5 min prior to intraperitoneal administration of $70 \mu \mathrm{mol} / \mathrm{kg}$ luteolin or normal saline in mice. Six hours later, the mice were sacrificed and used to collect BAL fluid for leukocyte counts. (B) Lung permeability was determined by quantitating the protein content in cell-free BAL. Values are expressed as means \pm SD. $n=5$. ${ }^{\mathrm{b}} P<0.05$ vs LPS-challenged control values (column 2 ).

caused an increase in neutrophil chemotaxis in vitro $(P<0.01)$. This response was attenuated by luteolin in a concentrationdependent manner with an $\mathrm{IC}_{50}$ value of $0.2 \pm 0.1 \mu \mathrm{mol} / \mathrm{L}$ (Figure 3A). During the assay, cell viability was $>95 \%$ in the treatment with testing different concentrations of luteolin (assessed by lactate dehydrogenase efflux, data not shown). 
ROS released from activated neutrophils play an important role in the initiation/propagation of microvascular permeability change and inflammation in LPS-induced ALI ${ }^{[30]}$. Stimulation of neutrophils with $1 \mu \mathrm{mol} / \mathrm{L}$ fMLP and $10 \mathrm{nmol} / \mathrm{L}$ PMA evoked superoxide anion generation. Luteolin had an inhibitory effect against fMLP-induced superoxide anion generation, with an $\mathrm{IC}_{50}$ value of $2.2 \pm 0.8 \mu \mathrm{mol} / \mathrm{L}$. However, no effect on PMA-induced superoxide anion generation was observed (Figure 3B). The results showed that luteolin was capable of inhibiting chemoattractant-induced neutrophil chemotaxis and the respiratory burst.
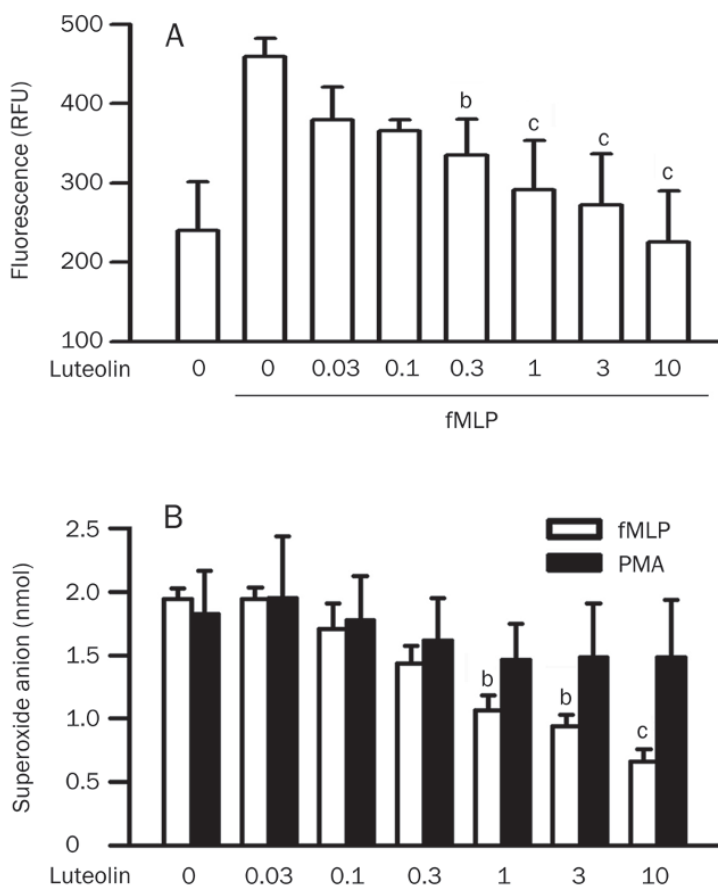

Figure 3. Effects of luteolin on chemotaxis and respiratory burst in fMLPstimulated neutrophils. (A) Calcein-loaded cells were incubated with DMSO or various concentrations of luteolin $(0.03-10 \mu \mathrm{mol} / \mathrm{L})$ for $10 \mathrm{~min}$. Cells were then placed in FluoroBlok Inserts in the presence or absence of $0.1 \mu \mathrm{mol} / \mathrm{L}$ fMLP for $2 \mathrm{~h}$. The fluorescence intensity in the lower chamber was determined. Values are expressed as means \pm SD. $n=4$. ${ }^{\mathrm{b}} P<0.05,{ }^{\mathrm{c}} P<0.01$ vs activated control values (column 2). (B) Cells were preincubated with DMSO or various concentrations of luteolin (0.03-10 $\mu \mathrm{mol} / \mathrm{L})$ for $10 \mathrm{~min}$ in the presence of dihydrocytochalasin $B(5 \mathrm{mg} / \mathrm{mL})$ prior to stimulation with $1 \mu \mathrm{mol} / \mathrm{L}$ fMLP. The superoxide anion generation was then determined. Values are expressed as means \pm SD. $n=4$. ${ }^{\mathrm{b}} P<0.05,{ }^{\mathrm{c}} P<0.01$ vs activated control values (column 1 ).

Effects of luteolin on fMLP-stimulated p38 MAPK phosphorylation

p38 MAPK plays an important role in LPS-induced $\mathrm{ALI}^{[31]}$ and in $\mathrm{fMLP}$-induced neutrophil chemotaxis and the respiratory burst $^{[32,33]}$. To examine the effect of luteolin on p38 MAPK, the phosphorylation of p38 MAPK in fMLP-stimulated neutrophils was analyzed by Western blotting. fMLP stimulation induced an increase in p38 MAPK phosphorylation $(1.9 \pm 0.2$ fold, $P<0.01)$. The inhibitory effect of luteolin on fMLPincreased p38 MAPK phosphorylation was observed only at concentrations of luteolin up to $30 \mu \mathrm{mol} / \mathrm{L}$ (61\% inhibition) (Figure 4). The $\mathrm{IC}_{50}$ values were 100- and 10-fold higher than those required for chemotaxis and for the respiratory burst, respectively.
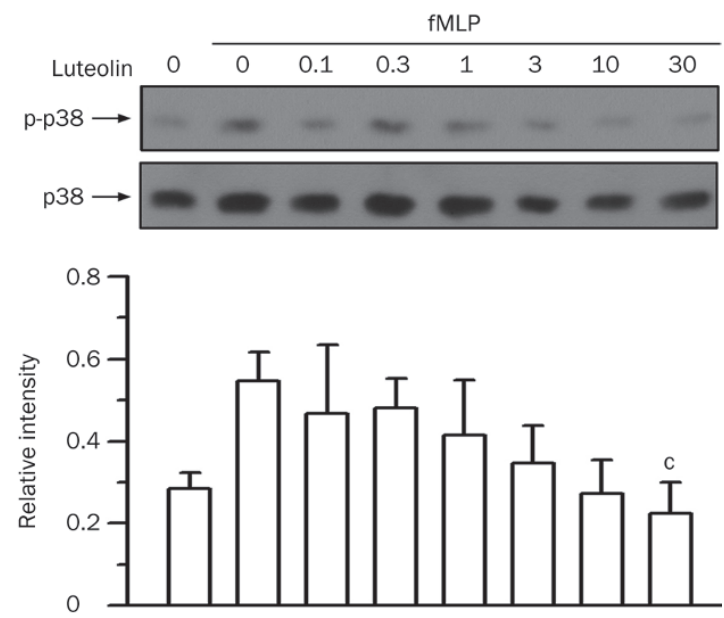

Figure 4. Effect of luteolin on p38 MAPK activation in $\mathrm{MMLP}$ stimulated neutrophils. Cells were preincubated with DMSO or various concentrations of luteolin $(1-30 \mu \mathrm{mol} / \mathrm{L})$ for $10 \mathrm{~min}$ in the presence of dihydrocytochalasin $B(5 \mu \mathrm{g} / \mathrm{mL})$ before stimulation with $1 \mu \mathrm{mol} / \mathrm{L} \mathrm{fMLP}$ or no stimulation for $1 \mathrm{~min}$. Cell lysates were immunoblotted with antiphospho-p38 MAPK (p-p38) antibody. The blot was then stripped and reprobed with anti-p38 MAPK (p38) antibody. The immunointensity ratio of p-p38 to p38 was calculated. Values are expressed as means \pm SD. $n=3$. ${ }^{\mathrm{b}} P<0.05$ vs activated control values (lane 2 ).

\section{Effects of luteolin on fMLP-stimulated ERK pathway}

The ERK pathway participates in chemoattractant-induced neutrophil chemotaxis and the respiratory burst ${ }^{[32,33]}$ and in LPS-induced ALI ${ }^{[31]}$. Stimulation of neutrophils with fMLP resulted in an increase in the phosphorylation of ERK $(P<0.01)$. Luteolin reduced the fMLP-induced ERK phosphorylation in a concentration-dependent manner, with an $\mathrm{IC}_{50}$ value of $5.4 \pm 2.2 \mu \mathrm{mol} / \mathrm{L}$ (Figure 5). Activation of ERK is mediated through its phosphorylation by MEK in response to various stimuli $^{[34]}$. Therefore, we next examined the effect of luteolin on the phosphorylation of MEK. As shown in Figure 6, MEK phosphorylation was weak in vehicle-treated cells, whereas a visible band was detected in response to fMLP stimulation $(P<0.01)$. Luteolin decreased the fMLP-induced MEK phosphorylation in a concentration-dependent manner, with an $\mathrm{IC}_{50}$ value of $0.1 \pm 0.1 \mu \mathrm{mol} / \mathrm{L}$. These results suggest that the MEKand ERK-related pathways play key roles in luteolin-mediated attenuation of fMLP-induced neutrophilic responses.

\section{Effects of luteolin on fMLP-stimulated Akt phosphorylation}

Protein kinase B/Akt has been implicated in LPS-induced $\mathrm{ALI}^{[9]}$ and plays a critical role in neutrophil chemotaxis and the 

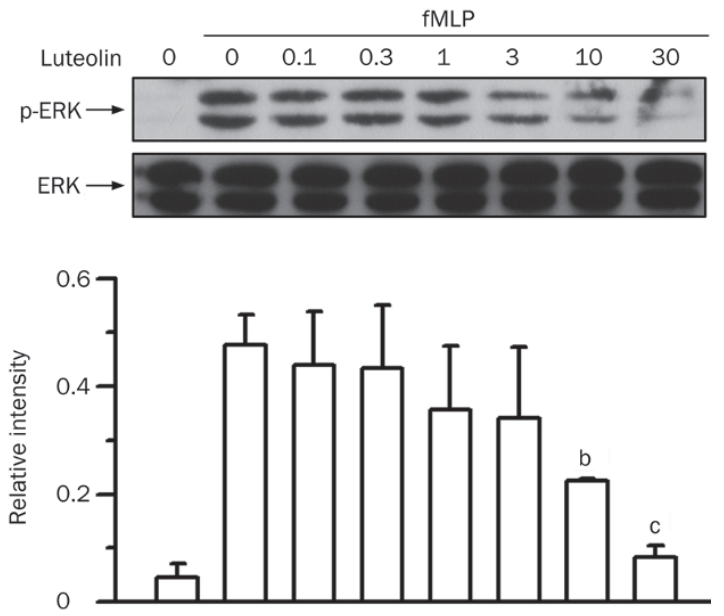

Figure 5. Effect of luteolin on ERK activation in fMLP-stimulated neutrophils. Cells were preincubated with DMSO or various concentrations of luteolin $(1-30 \mu \mathrm{mol} / \mathrm{L})$ for $10 \mathrm{~min}$ in the presence of dihydrocytochalasin B $(5 \mu \mathrm{g} / \mathrm{mL})$ before stimulation with $1 \mu \mathrm{mol} / \mathrm{L}$ fMLP or no stimulation for $1 \mathrm{~min}$. Cell lysates were immunoblotted with anti-phospho-ERK (P-ERK) antibody. The blot was then stripped and reprobed with anti-ERK (ERK) antibody. The immunointensity ratio of $\mathrm{p}$-ERK to ERK was calculated. Values are expressed as means \pm SD. $n=3 .{ }^{b} P<0.05,{ }^{c} P<0.01$ vs activated control values (lane 2).
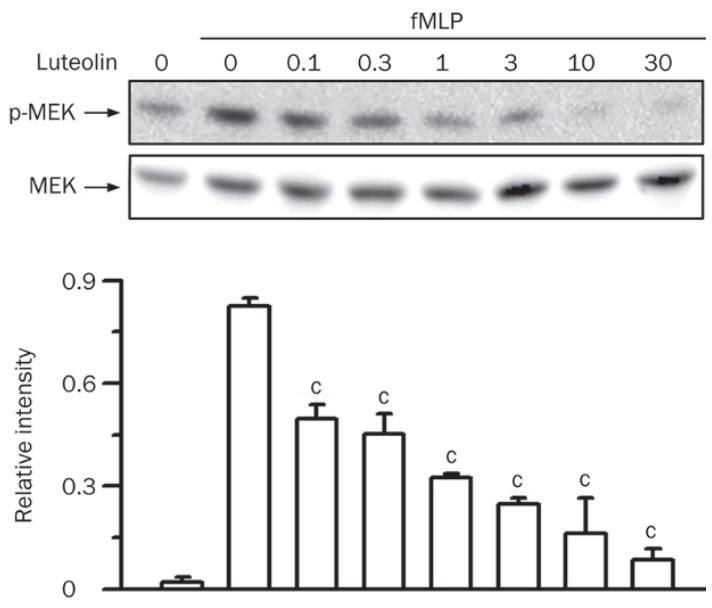

Figure 6. Effect of luteolin on MEK activation in fMLP-stimulated neutrophils. Cells were preincubated with DMSO or various concentrations of luteolin (1-30 $\mu \mathrm{mol} / \mathrm{L})$ for $10 \mathrm{~min}$ in the presence of dihydrocytochalasin B $(5 \mu \mathrm{g} / \mathrm{mL})$ before stimulation with $1 \mu \mathrm{mol} / \mathrm{L}$ fMLP or no stimulation for $1 \mathrm{~min}$. Cell lysates were immunoblotted with anti-phospho-MEK (p-MEK) antibody. The blot was then stripped and reprobed with anti-MEK (MEK) antibody. The immunointensity ratio of p-MEK to MEK was calculated. Values are expressed as means \pm SD. $n=3$. ${ }^{c} P<0.01$ vs activated control values (lane 2).

respiratory burst ${ }^{[35]}$. fMLP stimulation of neutrophils led to an increase in Akt phosphorylation $(P<0.01)$. Luteolin attenuated the Akt phosphorylation in a concentration-dependent manner, with an $\mathrm{IC}_{50}$ value of $1.8 \pm 1.0 \mu \mathrm{mol} / \mathrm{L}$ (Figure 7). These results suggest that the Akt-related pathways might actively
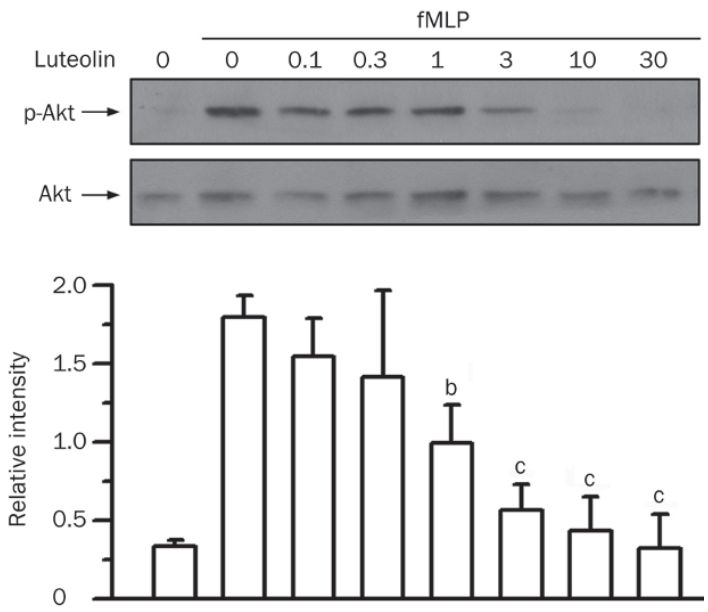

Figure 7. Effect of luteolin on Akt activation in fMLP-stimulated neutrophils. Cells were preincubated with DMSO or various concentrations of luteolin (1-30 $\mu \mathrm{mol} / \mathrm{L})$ for $10 \mathrm{~min}$ in the presence of dihydrocytochalasin B $(5 \mu \mathrm{g} / \mathrm{mL})$ before stimulation or no stimulation with $1 \mu \mathrm{mol} / \mathrm{L}$ fMLP for $1 \mathrm{~min}$. Cell lysates were immunoblotted with anti-phospho-Akt (p-Akt) antibody. The blot was then stripped and reprobed with anti-Akt (Akt) antibody. The immunointensity ratio of $p$-Akt to Akt was calculated. Values are expressed as means \pm SD. $n=3 .{ }^{b} P<0.05,{ }^{c} P<0.01$ vs activated control values (lane 2).

participate in luteolin-mediated attenuation of fMLP-induced neutrophilic responses.

Effects of Iuteolin on LPS-stimulated MEK, ERK, and Akt phosphorylation

In parallel with LPS-induced injury, the effects of luteolin were also investigated in LPS-stimulated neutrophils. Like fMLP, LPS stimulation induced elevated phosphorylation of MEK (4.0 \pm 0.7 fold, $P<0.01)$, ERK (7.1 \pm 1.5 fold, $P<0.01)$, and Akt $(3.5 \pm 1.0$ fold, $P<0.01)$. The increased phosphorylation was significantly attenuated by luteolin (Figure 8).

\section{Discussion}

An essential feature of experimental ALI is the presence of profound vascular leakage with movement of fluid and macromolecules into the interstitium and air space, events that directly contribute to the severe physiological derangements characteristic of this disorder. The impairment of pulmonary vascular barrier function enhances the transendothelial diapedesis of leukocytes into lung parenchymal tissues, further contributing to vascular and alveolar dysfunction in $\mathrm{ALI}^{[9]}$. In the present study, we found that pretreatment or posttreatment with luteolin inhibited the leukocyte influx and pulmonary permeability of LPS-induced ALI in mice, as evidenced by the decrease in leukocytes and protein content in the BAL fluid. This animal study suggests that luteolin has a beneficial effect against experimental ALI induced by LPS. Furthermore, the attenuation of peripheral leukocyte infiltration indicates the potential involvement of an immunosuppressive mechanism in luteolin-mediated 


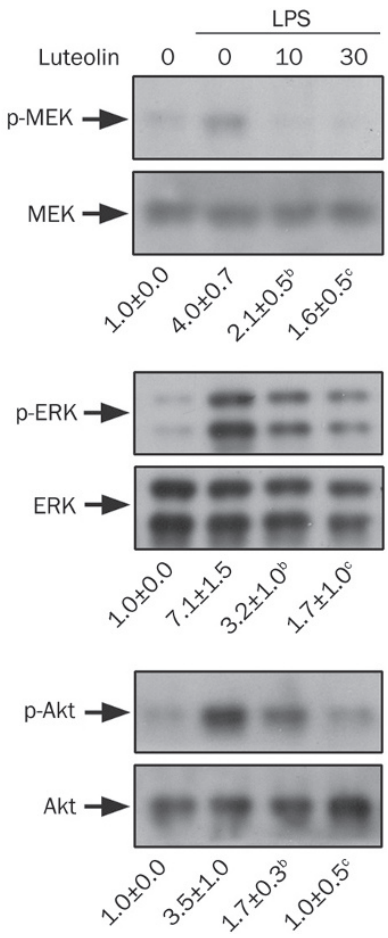

Figure 8. Effect of luteolin on MEK, ERK, and Akt activation in LPSstimulated neutrophils. Cells were preincubated with DMSO or various concentrations of luteolin (10 and $30 \mu \mathrm{mol} / \mathrm{L}$ ) for $10 \mathrm{~min}$ before stimulation with $100 \mathrm{ng} / \mathrm{mL}$ LPS or no stimulation for $1 \mathrm{~h}$. Cell lysates were subjected to Western blot analysis using antibodies against phosphorylated and total MEK, ERK, and Akt. The immunointensity ratio of the phosphorylated to total protein was calculated. The ratio of the control group was defined as 1.0. Values are expressed as means \pm SD. $n=3$. ${ }^{\mathrm{b}} P<0.05,{ }^{\mathrm{c}} P<0.01$ vs activated control values (lane 2 ).

protection. However, further in vivo studies will be needed to clarify the exact protective mechanism and the target molecule(s).

Accumulating evidence suggests that neutrophils play a critical role in $\mathrm{ALI}^{[5,6]}$. In the early stage, neutrophils are the predominant leukocyte population in the infiltrates after intratracheal LPS instillation ${ }^{[28,36]}$. Following the migration of neutrophils across the endothelium and epithelium into the alveolar space and their subsequent activation, they release a variety of cytotoxic and proinflammatory mediators. The magnification of these events upon the recruitment of additional inflammatory cells and the continuous production of cytotoxic mediators will ultimately lead to air space epithelial injury and respiratory failure ${ }^{[5]}$. Therefore, it is reasonable to hypothesize that neutrophils might be a potential intervention target and may play a critical role in the protective action of luteolin against LPS-induced ALI. fMLP, a bacterial peptide, is an effective chemoattractant and stimulator for neutrophils in vitro ${ }^{[25]}$. We found that luteolin significantly inhibited fMLP-induced neutrophil chemotaxis and superoxide anion generation. These in vitro findings suggest that the protective effect of luteolin against LPS-induced ALI might be mediated via the suppression of neutrophil infiltration and activation.

NADPH oxidase contains several subunits that include both membrane-bound cytochrome $b_{558}$ ( $222^{\text {phox }}$ and gp91 $\left.91^{\text {phox }}\right)$ and cytosolic subunits ( $\left.\mathrm{p} 40^{\text {phox }}, \mathrm{p} 47^{\text {phox }}, \mathrm{p} 67^{\text {phox }}\right)$. When appropriately stimulated, cytosolic subunits of NADPH oxidase translocate to cellular membranes, interact with activated small GTPase Rac2, and assemble into an active complex. NADPH oxidase is responsible for the abrupt consumption of oxygen, termed the respiratory burst in neutrophils, yielding superoxide anion, which is subsequently transformed into other $\operatorname{ROS}^{[37,38]}$. Interestingly, luteolin attenuated the fMLPinduced respiratory burst in neutrophils but had a negligible effect on PMA-mediated stimulation. Unlike fMLP, which triggers $\mathrm{G}$ protein-mediated signaling, PMA is a membranepermeable protein kinase $\mathrm{C}$ activator ${ }^{[39]}$. The interference of initial stimulation or intracellular signal transduction steps downstream of receptor activation is possible. Currently, the discrepancy between fMLP- and PMA-mediated responses has not been resolved.

Signals emanating from different cues converge on signaling molecules such as MAPK and Akt through the modulation of protein phosphorylation events, which in turn lead to the phosphorylation and activation of various downstream effectors and transcription factors. In general, fMLP stimulates a complex series of signal transduction events that culminate in the activation of neutrophils, in which MAPK cascades and PI3K/Akt pathways are essential for the respiratory burst and chemotaxis ${ }^{[32,33,38]}$. Three major mammalian MAPK cascades have been identified, including ERK, p38 MAPK and JNK ${ }^{[38]}$. Each MAPK cascade is activated by a distinct kinase cascade in which a MAPK-kinase kinase, also called MAPKKK or MEKKK, phosphorylates and activates a downstream dual-specificity MAPK-kinase, also called MAPKK or MEKK, which in turn stimulates MAPK activity through the dual phosphorylation of the Thr-Glu-Tyr motif within its activation loop. MEK is an upstream kinase of ERK ${ }^{[34]}$. Several studies have shown that both the ERK pathway and p38 MAPK, but not JNK, are required for the fMLP-stimulated respiratory burst and chemotaxis ${ }^{[32,40-42]}$. On the other hand, the PI3K/Akt pathway has been implicated in LPS-induced $\mathrm{ALI}^{[9]}$ and plays an important role in neutrophil chemotaxis and the respiratory burst ${ }^{[35]}$. PI3Ks, which are lipid kinases, phosphorylate the 3-hydroxyl position of the inositol ring of phosphoinositides to generate phosphatidylinositol-3,4,5trisphosphate ${ }^{[43]}$. Akt, which functions downstream of PI3K, is activated by phosphatidylinositol-3,4,5-trisphosphate through serine and threonine phosphorylation ${ }^{[4,45]}$. The finding that a higher concentration of luteolin was required to inhibit the phosphorylation of p38 MAPK primarily precluded the involvement of p38 MAPK signaling. MEK, ERK, and Akt phosphorylation were attenuated by luteolin in fMLP-stimulated neutrophils in a parallel concentrationdependent manner, with $\mathrm{IC}_{50}$ values similar to those observed in the suppression of the respiratory burst, suggesting that MEK/ERK- and Akt-related signaling play a pivotal role. In comparison with fMLP, LPS is not an effective chemoattractant 
for neutrophils but can trigger an inflammatory cascade ${ }^{[46]}$. In the present study, we also found that luteolin attenuated LPSinduced MEK, ERK, and Akt phosphorylation in neutrophils. Recently, Schuh and Pahl ${ }^{[47]}$ used a specific inhibitor of MEK, U0126, to show that the ERK pathway plays an important role in LPS mediated pulmonary inflammation. These observations suggest that MEK/ERK and Akt could be critical targets for luteolin-mediated inhibitory effects in neutrophils.

In conclusion, luteolin has beneficial effects against LPSinduced ALI, as evidenced by an inhibition of leukocyte influx into the lung and lung permeability. Luteolin attenuates fMLP-induced neutrophil chemotaxis and the respiratory burst in vitro. The inhibitory mechanism of luteolin seems to be multifactorial. It is reasonable to propose that the inhibition of MEK/ERK- and PI3K/Akt-related pathways by luteolin represents a critical mechanism to attenuate neutrophil activation. However, the initial interacting targets of luteolin and additional anti-inflammatory mechanisms require further investigation.

\section{Acknowledgements}

This work was supported by grant CSMU-DAC-097-001 from the Da-Chien General Hospital and Chung Shan Medical University, Taiwan, China.

\section{Author contribution}

Jen-pei LEE performed the research. Yi-ching LI performed the research and wrote part of the paper. Hung-yi CHEN performed part of the research. Ruey-hseng LIN analyzed the data and preparations. Shiang-suo HUANG performed part of the research. Hui-ling CHEN did part of the preparations. Pai-chuan KUAN wrote part of the introduction. Maofang LIAO wrote part of the discussion. Chun-jung CHEN designed the research and wrote the paper. Yu-hsiang KUAN designed the research, performed part of the research, and wrote the paper.

\section{Abbreviations}

ALI, acute lung injury; BAL, bronchoalveolar lavage; ERK, extracellular signal regulated kinase 1/2; fMLP, formyl-Met-LeuPhe; HBSS, Hanks' balanced salt solution; JNK, c-Jun N-terminal kinase; LPS, lipopolysaccharide; MAPK, mitogen-activated protein kinase; MEK, MAPK/ERK kinase 1/2; NADPH, nicotinamide adenine dinucleotide phosphate; PI3K, phosphoinositide 3-kinase; PMA, phorbol myristate acetate; RFUs, relative fluorescence units; ROS, reactive oxygen species.

\section{References}

1 Ware LB, Matthay MA. The acute respiratory distress syndrome. N Engl J Med 2000; 342: 1334-49.

2 Brigham KL, Meyrick B. Endotoxin and lung injury. Am Rev Respir Dis 1986; 133: 913-27.

3 Mei SHJ, McCarter SD, Deng Y, Parker CH, Liles CW, Stewart DJ. Prevention of LPS-induced acute lung injury in mice by mesenchymal stem cells overexpressing angiopoietin 1. PLOS Med 2007; 4: 1525-7.

4 Moraes TJ, Zurawska JH, Downey GP. Neutrophil granule contents in the pathogenesis of lung injury. Curr Opin Hematol 2006; 13: 21-7.
5 Guo RF, Ward PA. Role of oxidants in lung injury during sepsis. Antioxid Redox Sign 2007; 9: 1991-2002.

6 Faurschou M, Borregaard N. Neutrophil granules and secretary vesicles in inflammation. Microbes Infect 2003; 5: 1317-27.

7 Klebano SJ. Myeloperoxidase: friend and foe. J Leukocyte Biol 2005; 77: 598-625.

8 Nauseef WM. How human neutrophils kill and degrade microbes: an integrated review. Immunol Rev 2007; 219: 88-102.

9 Abraham E. Neutrophils and acute lung injury. Crit Care Med 2003; 31: S195-9.

10 Lee JH, Ko WS, Kim YH, Kang HS, Kim HD, Choi BT. Antiinflammatory effect of the aqueous extract from Lonicera japonica flower is related to inhibition of NF-kappaB activation through reducing I-kappaBalpha degradation in rat liver. Int J Mol Med 2001; 7: 79-83.

11 López-Lázaro M. Distribution and biological activities of the flavonoid luteolin. Mini Rev Med Chem 2009; 9: 31-59.

12 Yu SL, Zhang L, Sun L. Flos Lonicerae's research progress. Lishizhen Med Mater Med Res 2002; 13: 498-9. Chinese.

13 Liu X, Zhang M, He L, Li YP, Kang YK. Chinese herbs combined with Western medicine for severe acute respiratory syndrome (SARS). Cochrane Database Syst Rev 2006; CD004882.

14 Wu CY, Jan JT, Ma SH, Kuo CJ, Juan HF, Cheng YS, et al. Small molecules targeting severe acute respiratory syndrome human coronavirus. Proc Natl Acad Sci USA 2004; 101: 10012-7.

15 Ko HC, Wei BL, Chiou WF. The effect of medicinal plants used in Chinese folk medicine on RANTES secretion by virus-infected human epithelial cells. J Ethnopharmacol 2006; 107: 205-10.

16 Kotanidou A, Xagorari A, Bagli E, Kitsanta P, Fotsis T, Papapetropoulos $A$, et al. Luteolin reduces lipopolysaccharide-induced lethal toxicity and expression of proinflammatory molecules in mice. Am J Respir Crit Care Med 2002; 165: 818-23.

17 Das M, Ram A, Ghosh B. Luteolin alleviates bronchoconstriction and airway hyperreactivity in ovalbumin sensitized mice. Inflamm Res 2003; 52: 101-6.

18 Tormakangas L, Vuorela P, Saario E, Leinonen M, Saikku P, Vuorela H. In vivo treatment of acute Chlamydia pneumoniae infection with the flavonoids quercetin and luteolin and an alkyl gallate, octyl gallate, in a mouse model. Biochem Pharmacol 2005; 70: 1222-30.

19 Comalada M, Ballester I, Bailon E, Sierra S, Xaus J, Galvez J, et al. Inhibition of pro-inflammatory markers in primary bone marrowderived mouse macrophages by naturally occurring flavonoids: analysis of the structure-activity relationship. Biochem Pharmacol 2006; 72: 1010-21.

20 Chen CY, Peng WH, Tsai KD, Hsu SL. Luteolin suppresses inflammation-associated gene expression by blocking NF-KB and AP-1 activation pathway in mouse alveolar macrophages. Life Sci 2007; 81: 1602-14.

21 Xagorari A, Papapetropoulos A, Mauromatis A, Economou M, Fotsis T, Roussos C. Luteolin inhibits an endotoxin-stimulated phosphorylation cascade and proinflammatory cytokine production in macrophages. J Pharmacol Exp Ther 2001; 296: 181-7.

22 Harris GK, Qian Y, Leonard SS, Sbarra DC, Shi X. Luteolin and chrysin differentially inhibit cyclooxygenase-2 expression and scavenge reactive oxygen species but similarly inhibit prostaglandin-E2 formation in RAW 264.7 cells. J Nutr 2006; 136: 1517-21.

23 Lu HW, Sugahara K, Sagara Y, Masuoka N, Asaka Y, Manabe M, et al. Effect of three flavonoids, 5,7,3',4'-tetrahydroxy-3-methoxy flavone, luteolin, and quercetin, on the stimulus-induced superoxide generation and tyrosyl phosphorylation of proteins in human neutrophil. Arch Biochem Biophys 2001; 393: 73-7.

24 Loke WM, Proudfoot JM, Stewart S, McKinley AJ, Needs PW, Kroon 
$\mathrm{PA}$, et al. Metabolic transformation has a profound effect on antiinflammatory activity of flavonoids such as quercetin: lack of association between antioxidant and lipoxygenase inhibitory activity. Biochem Pharmacol 2008; 75: 1045-53.

25 Wagner JG, Harkema JR, Roth RA. Pulmonary leukostasis and the inhibition of airway neutrophil recruitment are early events in the endotoxemic rat. Shock 2002; 17: 151-8.

26 Kuan YH, Lin RH, Chen YL, Tsao LT, Tzeng CC, Wang JP. Effective attenuation of acute lung injury in vivo and the formyl peptide-induced neutrophil activation in vitro by CYL-26z through the phosphoinositide 3-kinase gamma pathway. Biochem Pharmacol 2006; 72: 749-60.

27 Strieter RM, Kunkel SL, Keane MP, Standiford TJ. Chemokines in lung injury: Thomas A. Neff Lecture. Chest 1999; 116: 103S-110S.

28 Corteling R, Wyss D, Trifilieff A. In vivo models of lung neutrophil activation. Comparison of mice and hamsters. BMC Pharmacol 2002; 2: 1-8.

29 Speyer CL, Rancilio NJ, McClintock SD, Crawford JD, Gao H, Sarma JV, et al. Regulatory effects of estrogen on acute lung inflammation in mice. Am J Physiol Cell Physiol 2005; 288: C881-90.

30 Worthen GS, Nick JA. Leukocyte accumulation in the lung. In: Fishman AP, editor. vol.1. Pulmonary diseases disorders. New York: McGraw-Hill; 1998. p325-336.

31 Nick JA, Young SK, Brown KK, Avdi NJ, Arndt PG, Suratt BT, et al. Role of p38 mitogen-activated protein kinase in a murine model of pulmonary inflammation. J Immunol 2000; 164: 2151-9.

32 Zu YL, Qi J, Gilchrist A, Fernandez GA, Vazquez-Abad D, Kreutzer DL, et al. p38 mitogen-activated protein kinase activation is required for human neutrophil function triggered by TNF- $\alpha$ or FMLP stimulation. J Immunol 1998; 160: 1982-9.

33 Kuroki M, O'Flaherty JT. Differential effects of a mitogen-activated protein kinase kinase inhibitor on human neutrophil responses to chemotactic factors. Biochem Biophys Res Commun 1997; 232: 474-7.

34 Geest CR, Coffer PJ. MAPK signaling pathways in the regulation of hematopoiesis. J Leukoc Biol 2009; 86: 237-50.

35 Sasaki T, Irie-Sasaki J, Jones RG, Oliveira-dos-Santos AJ, Stanford WL, Bolon B, et al. Function of PI3Ky in thymocyte development, T cell activation, and neutrophil migration. Science 2000; 287: 1040-6.

36 Yeh CC, Kao SJ, Lina CC. The immunomodulation of endotoxin- induced acute lung injury by hesperidin in vivo and in vitro. Life Sci 2007; 80: 1821-31.

37 Babior BM, Lambeth JD, Nauseef W. The neutrophil NADPH oxidase. Arch Biochem Biophys 2002; 397: 342-4.

38 Selvatici R, Falzarano S, Mollica A, Spisani S. Signal transduction pathways triggered by selective formylpeptide analogues in human neutrophils. Eur J Pharmacol 2006; 534: 1-11

39 Majumdar S, Kane LH, Rossi MW, Volpp BD, Nauseef WM, Korchak HM. Protein kinase $C$ isotypes and signal-transduction in human neutrophils: selective substrate specificity of calcium-dependent betaPKC and novel calcium-independent nPKC. Biochim Biophys Acta 1993; 1176: 276-86.

40 El Benna J, Faust RP, Johnson JL, Babior BM. Phosphorylation of the respiratory burst oxidase subunit $\mathrm{p} 47 \mathrm{phox}$ as determined by twodimensional phosphopeptide mapping. Phosphorylation by protein kinase $\mathrm{C}$, protein kinase $\mathrm{A}$ and a mitogen activated protein kinase. J Biol Chem 1996; 271: 6374-8.

41 Coxon PY, Rane MJ, Uriarte S, Powell DW, Singh S, Butt W, et al. MAPK-activated protein kinase-2 participates in p38 MAPK-dependent and ERK-dependent functions in human neutrophils. Cell Signal 2003; 15: 993-1001.

42 Heuertz RM, Tricomi SM, Ezekiel UR, Webster RO. C-reactive protein inhibits chemotactic peptide-induced p38 mitogen-activated protein kinase activity and human neutrophil movement. J Biol Chem 1999; 274: 17968-74.

43 Vanhaesebroeck B, Leevers SJ, Ahmadi K, Timms J, Katso R, Driscoll $\mathrm{PC}$, et al. Synthesis and function of 3-phosphorylated inositol lipids. Annu Rev Biochem 2001; 70: 535-602.

44 Wymann MP, Zvelebil M, Laffargue M. Phosphoinositide 3-kinase signalling-which way to target? Trends Pharmacol Sci 2003; 24: 366-76.

45 Sale EM, Sale GJ. Protein kinase B: signalling roles and therapeutic targeting. Cell Mol Life Sci 2008; 65: 113-27.

46 Carroll EJ, Mueller R, Panico L. Chemotactic factors for bovine leukocytes. Am J Vet Res 1982; 43: 1661-4.

47 Schuh K, Pahl A. Inhibition of the MAP kinase ERK protects from lipopolysaccharide-induced lung injury. Biochem Pharmacol 2009; 77: 1827-34. 